Saudi Journal of Biomedical Research

Abbreviated Key Title: Saudi J Biomed Res ISSN 2518-3214 (Print) |ISSN 2518-3222 (Online)

\title{
The Influence of Mercury on Renal Function Test among Mining Gold Workers in River Nile State, Sudan
}

Zakaria Albadwi Alagmi Mohammed ${ }^{1}$, Nassr Eldin Mohammed Ahmed ${ }^{1}$, Mosab Nouraldein Mohammed Hamad ${ }^{2 *}$, Yassin Saad El hossin ${ }^{1}$, Nada Alamin ${ }^{1}$, Amna Osman

${ }^{1}$ Faculty of Medical Laboratory Sciences, Alzaiem Alazhari University, Khartoum North, Sudan

${ }^{2}$ Faculty of Health Science, Elsheikh Abdallah Elbadri University, Berber, Sudan

DOI: $10.36348 /$ sjbr.2021.v06i04.002

| Received: 12.02.2021 | Accepted: 07.04.2021 | Published: 13.04.2021

*Corresponding author: Mosab Nouraldein Mohammed Hamad

\section{Abstract}

Background: Mercury is found in liquid form at room temperature, but it has a very high vapor pressure, which causes it to be more toxic that it would be otherwise. In its gaseous state, mercury, $\mathrm{Hg}(\mathrm{g})$, is highly toxic. Because it dissolves very easily in lipids, and is absorbed very easily by red blood cells and nerve cells. The study aimed to measure of serum mercury and renal function test among case study and control. Method: Blood (serum), Personal protection equipments (PPE) such as gloves were used. Blood was drawn directly from venous port $.5 \mathrm{ml}$ of whole blood was collected; Samples were centrifuged at 3000-4000 RPM for 5 minutes. Serum was collected in plain containers, and then stored at refrigerator between (2-8 C). Total of 70 participant age (20 -50 years 50 as workers mining gold and 20 as control serum collected for each participants and mercury determined by DMA-80(direct mercury analyzer) and serum urea, creatinine, uric acid by biosystem analyzer A15. Result: Results statistically analysis mercury p. value (0.001). Urea P.value (0.571). Creatinine P. value (0.022). Uric acid P.value $(<0.001)$. Conclusion: This study established that there is a significant increase in the levels of serum mercury and, creatinine and uric acid levels between case and normal control groups $(\mathrm{p}<0.05)$.The new workers are more exposed to mercury than the older workers.

Keywords: Mercury, Renal Function Test, Mining gold, River Nile State, Sudan.

Copyright (C) 2021 The Author(s): This is an open-access article distributed under the terms of the Creative Commons Attribution 4.0 International License (CC BY-NC 4.0) which permits unrestricted use, distribution, and reproduction in any medium for non-commercial use provided the original author and source are credited.

\section{INTRODUCTION}

Mercury $(\mathrm{Hg})$, also called quicksilver, is a heavy, silvery metal. Mercury is one of two (the other is bromine) elements that are liquid at room temperature and pressure. Extremely toxic mercury compound, dimethyl mercury, looks like water but is three times as dense. There are three naturally occurring oxidation states of mercury: $\mathrm{Hg}(0), \mathrm{Hg}$ (I), and $\mathrm{Hg}(\mathrm{II})$. Organic mercury refers to forms of mercury bound to a carbon atom, with mercury usually in $\mathrm{Hg}$ (II) oxidation state [1, 2]. Mercury is released to atmosphere as a product of the natural out gassing of rock (30,000 tons per year) and as a fungicide (6,000 tons per year), and it is incorporated into dental amalgams (90 tons per year). Mercury is also used in electrical switches [3]. Mercury occurs naturally in the environment and exists in several forms. These forms can be organized under three headings: metallic mercury (also known as elemental mercury), inorganic mercury, and organic mercury. Metal llic mercury is a shiny, silver-white metal that is a liquid at room temperature. Metallic mercury is the elemental or pure form of mercury (i.e., it is not combined with other elements) [4]. Metallic mercury metal is the familiar liquid metal used in thermometers and some electrical switches. At room temperature, some of the metallic mercury [5]: Mercury $(\mathrm{Hg})$ is used in gold mining to extract gold from ore by forming-amalgam $\|-\mathrm{a}$ mixture composed of approximately equal parts mercury and gold. Approximately 15 million people, including approximately 3million women and children, participate in artisanal small-scale gold mining (ASGM).

Familiar liquid metal used in thermometers and some electrical switches. At room temperature, some of the metallic mercury: Mercury $(\mathrm{Hg})$ is used in gold mining to extract gold from ore by forming —amalgam\|—a mixture composed of approximately equal parts mercury and gold. Approximately 15 million people, including approximately 3 million women and children, participate in artisanal small-scale gold mining (ASGM) in developing countries. Thirty-seven percent 
of global air emissions of $\mathrm{Hg}$ are produced by ASGM [6].

Most of the mercury found in the environment is in the form of metallic mercury and inorganic mercury compounds. Metallic and inorganic mercury enters the air from mining deposits of ores that contain mercury, from the emissions of coal-fired power plants, from burning municipal and medical waste [7], from the production of cement, and from uncontrolled releases in factories that use mercury. Metallic mercury is a liquid at room temperature, but some of the metal will evaporate into the air and can be carried long distances. In air, the mercury vapor can be changed into other forms of mercury [8], and can be further transported to water or soil in rain or snow. Inorganic mercury may also enter water or soil from the weathering of rocks that contain mercury [9].

\section{Rationale}

Many people now days working as gold miners activities using mercury, when they came to the clinics with some symptoms, which might be related to mercury toxicity. There is limited or non-published data in Sudan regarding the biochemistry parameters among mining workers. This study was conducted to determine the effect of mercury on biochemical parameters such as renal function test.

\section{OBJECTIVES}

General objectives

To determine the effect of mercury on RFT among gold mining workers in River Nile State in Alabedia market.

\section{Specific objectives}

a. To measure the mercury and urea, creatinine, uric acid among mining workers and control.

b. To find out the correlation between mercury gold mining. level and the duration of

\section{MATERIALS \& METHOD \\ Study design \\ Cross sectional study.}

\section{Study area}

This study was conducted in Alabedia marked of gold extraction.

\section{Study period}

$$
\text { Aug. } 2017 \text { - Apr- }
$$

\section{Study subject}

The present study conducted among the male comes to Alabedia market who extraction of gold a total of 50 subject enrolled from the 18 to 40 years of age group.
Sample size

This study included a total of (70) samples.

(50) Group under study and (20) as control group.

\section{Inclusion criteria}

Male using mercury for extraction of gold

\section{Exclusion criteria}

There is no women working in a gold mining

\section{Ethical Consideration}

Ethical clearance was obtained from Alazhri University to National Security and Intelligence Service from whom we received approval letter to collect samples of mercury from gold mining workers.

Sample size

This study included a total of (70) samples. (50) Group under study and (20) as control group.

\section{Data collection technique}

Data collected through well- structured questionnaire.

\section{METHOD}

\section{Specimen required}

Blood (serum), Personal protection equipments (PPE) such as gloves were used. Blood was drawn directly from venous port $.5 \mathrm{ml}$ of whole blood was collected Samples were centrifuged at at 3000-4000 RPM for 5 minutes. Serum was collected in plain containers, and then stored at refrigerator between (2-8 C).

\section{Analysis of samples}

- Samples were analyzed using A25 Biosystem analyzer for measuring serum urea .creatinine .uric acid and serum mercury by DMA 80

- Samples: human serum.

- Stability: patient samples to be investigated can generally be store at $2 \mathrm{C}$ to $8 \mathrm{C}$ for up 7 days.

Quality control: It is recommended to use the biochemistry control serum level 1 and level 2 to verify performance: of the measurement procedure.

\section{Interpretation of result Results were interpreted as follow:}

- Serum urea level $15-39 \mathrm{mg} / \mathrm{dl}$

- Serum creatinine $0.6-1.1 \mathrm{mg} / \mathrm{dl}$

- Serum uric acid $3.5-7.0 \mathrm{mg} / \mathrm{dl}$

- Serum mercury level 0-10 ng/ml

\section{STATISTICAL ANALYSIS}

Statistical analysis was performed on data using computer SPSS software package and results expressed as mean and standard deviation. Participant test was used to determine the significant difference between the mean values with $\mathrm{p}$ value set at $\mathrm{p}<0.05$. 


\section{RESULT}

Total of (70) subjects were enrolled in this study (50) mining workers exposed to mercury and (20) normal control not exposed to mercury for comparison. The case and normal control groups were selected according to inclusion criteria, the case and control mean age was 28 years.

Table (1) shows the comparison of mean (SD), mean difference (MD), lower and upper $95 \%$ confidence interval of mercury, urea, creatinine and uric acid levels between among case and normal control groups. There were significant means difference of mercury, creatinine and uric acid levels between case and normal control groups $(\mathrm{p}<0.05)$. However, there was insignificance MD of urea levels between case and normal control. This result reflects that the effect of mining on mercury, creatinine and uric acid levels among workers.

Table-1: Comparison of mean (SD) and mean difference of mercury, urea, creatinine and uric acid levels between case $(n=50)$ and normal control $(n=20)$

\begin{tabular}{|l|l|l|l|l|}
\hline GROUP & \multicolumn{4}{l|}{ MEAN SD AND MD CI } \\
\hline & CASE & CONTROL & CI & P.V \\
\hline MERCURY & $62.17(104.53)$ & $0.72(0.62)$ & $61.45(31.74,91.16$ & $>0.001$ \\
\hline UREA & $2.6 .18(7.93)$ & $27.30(6.07)$ & $-1.12(-4.67,2.42)$ & 0.571 \\
\hline CREATININE & $0.86(0.16)$ & $0.75(0.18)$ & $0.1(0.02,0.19)$ & 0.022 \\
\hline URIC ACID & $7.43(1.88)$ & $5.21(1.17)$ & $2.22(1.31,3.12)$ & $>0.001$ \\
\hline
\end{tabular}

Independent t. test was applied. P-value set as 0.05 is significant

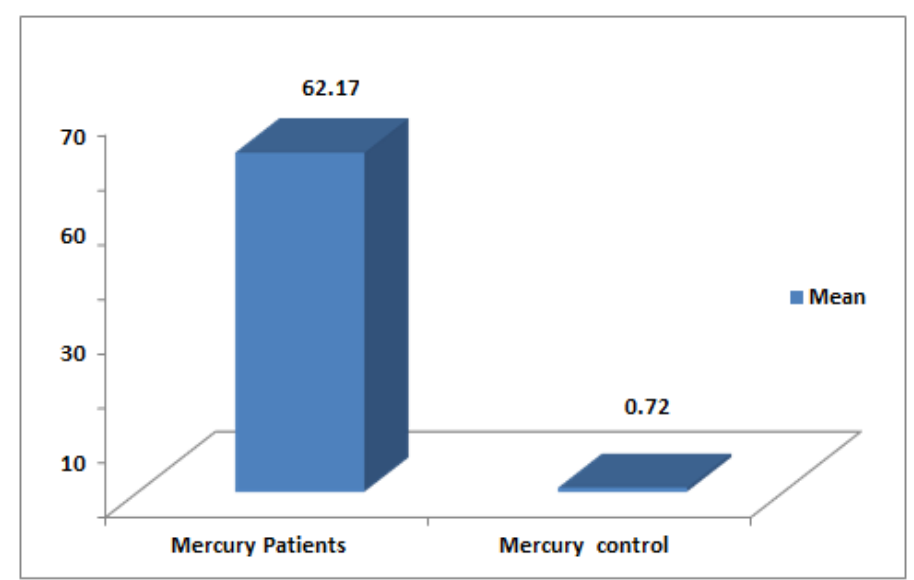

Fig-1: Comparison of mean of mercury level between case $(n=50)$ andnormal control $(n=20)$

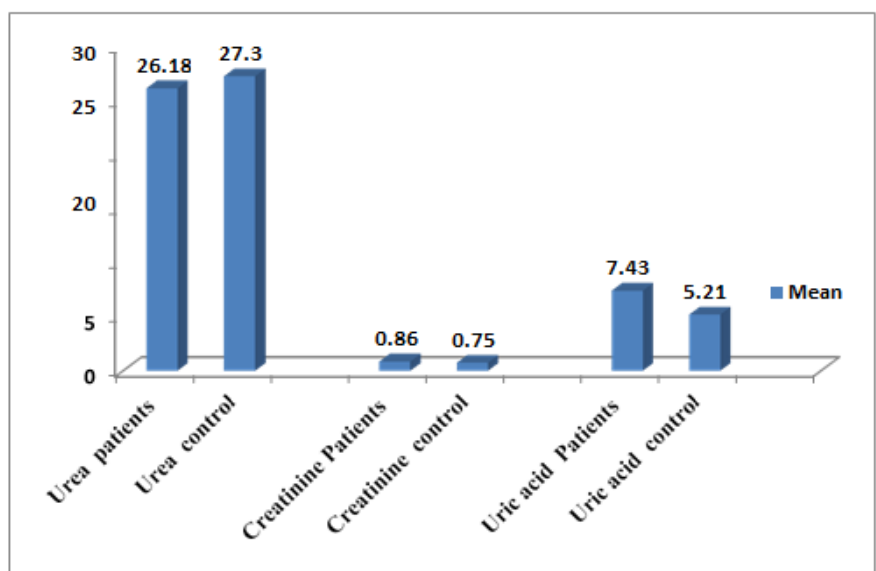

Fig-2: Comparison of means of urea, creatinine and uric acid levels betweencase $(n=50)$ and normal control $(n=20)$

Table-2: Shows the comparison of mean, standard deviation (SD), meandifference (MD), upper and lower $95 \%$ confidence interval of mercury of case with respect to their duration of work:

\begin{tabular}{|l|l|l|l|l|}
\hline Duration of work & Number & Mean (SD) of mercury & MD $(\mathbf{9 5 \%}$ CI) & p-value \\
\hline$<3$ years & 29 & $78.7627(126.59934)$ & $38.73259(98.43318$, & 0.021 \\
\hline$\geq 3$ years & 21 & $40.0301(57.73843)$ & $-20.96799)$ & \\
\hline
\end{tabular}


There was significant mean difference of mercury level between the cases ( $p$-value<0.05) with respect to their duration of work reflecting that newer worker are more exposed to mercury than older ones.

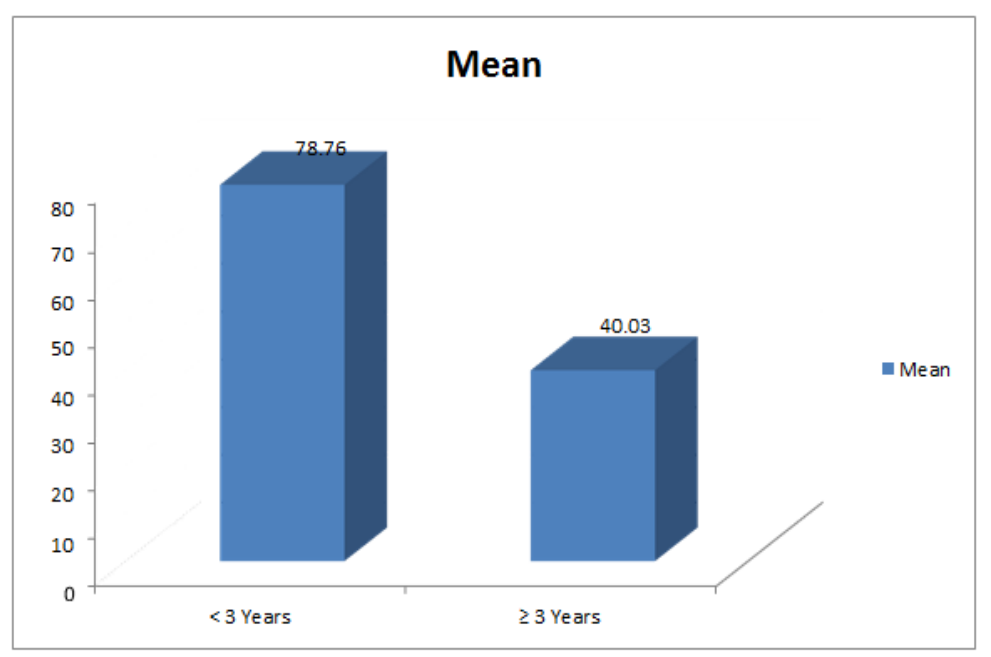

Fig-3: Shows comparison of mean of mercury level between the cases with respect to their duration of work

Fig-4: Shows the association between mercury level and duration among mining workers, the results showed weak insignificant negative association $\left(r^{2}=0.014\right)$ and $(p=0.412)$. This may reflect that the new workers more exposed to mercury than older subject.

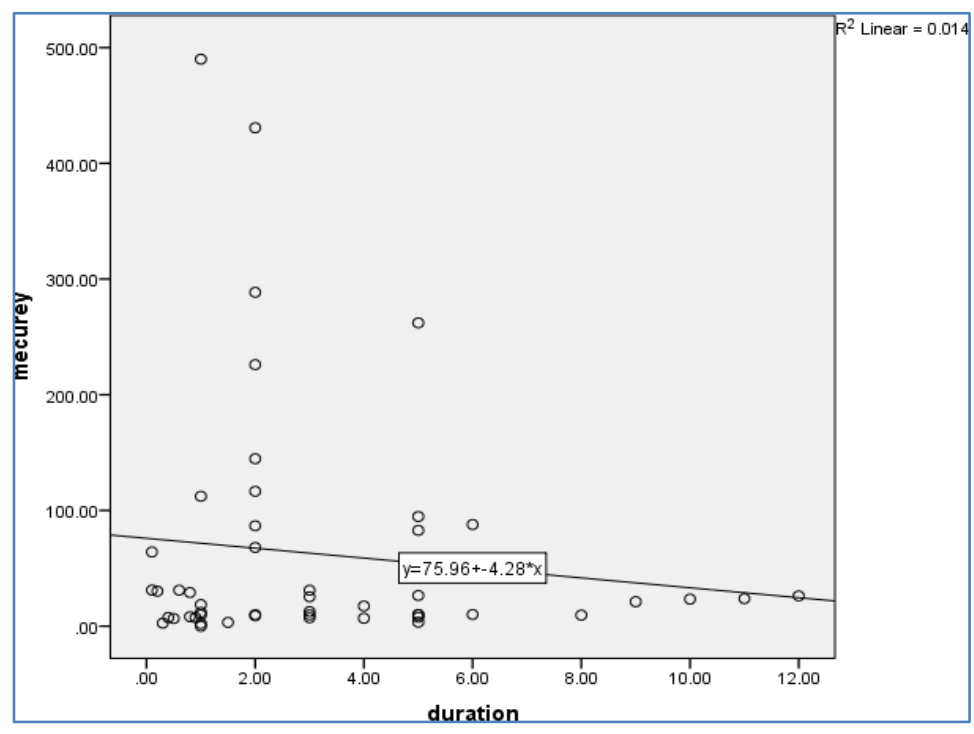

Fig-4: The relationship between mercury and duration among miningworkers $(n=$

\section{DISCUSSION}

The result shows the comparison of mean (SD), mean difference (MD), lower and upper 95\% confidence interval of mercury (P. value $>0.001)$. This result was agreed to De Kom et al. which found that mercury had significant effect on mercury. Urea, creatinine and uric acid levels between among case and normal control groups. There were significant means difference of mercury, creatinine and uric acid levels between case and normal control groups $(p<0.05)$. This result with agreed with finding reported by Augusti et al. However, there was insignificance MD of urea levels between case and normal control. This result reflects that the effect of mining on mercury, creatinine and uric acid levels among workers.

\section{CONCLUSION}

This study established that there is a significant increase in the levels of serum mercury and compared to control group. The new workers are more exposed to mercury than the older workers because the new workers have no experience to contact with gold mining extraction. 


\section{RECOMMENDATION}

- The new employees should be aware about the hazards of mercury to avoid over exposure.

- The management should provide regular campaign to increase the worker awareness.

- Gold workers should wear protective suit.

- The method of extracting gold is rudimentary and random. Therefore, it is recommended that companies extract gold in modern, scientific and distant ways from workers and citizens.

\section{REFERENCES}

1. Drash, G.A., Mercury. In Seiler H.G., S.A., Sigel, H. (1994). Eds. Handbook on metals in clinical and analytical chemistry. New York: Marcel Dekker, $23 ; 479-493$.

2. https://www.sciencemag.org/news/1997/06/mercu ry-poisoning-kills-lab-chemist.

3. Lund, M. E., Banner, W., Clarkson Thomas, W., \& Berlin, M. (1984). Treatment of acute methylmercury ingestion by hemodialysis with $\mathrm{N}$ acetylcysteine (Mucomyst) infusion and 2, 3dimercaptopropane sulfonate. Journal of
Toxicology: Clinical Toxicology, 22(1), 31-49.

4. Rice, K. M., Walker Jr, E. M., Wu, M., Gillette, C., \& Blough, E. R. (2014). Environmental mercury and its toxic effects. Journal of preventive medicine and public health, 47(2), 74.

5. https://emsiteacherworkshop.stanford.edu/pages/w orkshopresources/Toxicology\%20of\%20Mercuyp df

6. Gibb, H., \& O’Leary, K. G. (2014). Mercury exposure and health impacts among individuals in the artisanal and small-scale gold mining community: a comprehensive review. Environmental health perspectives, 122(7), 667-672.

7. Dunn, J.D., \& Clarkson, T.W. (1980). Does mercury exhalation signal demethylation of methyl mercury.Health Physics, 38(3), 411-414..

8. Adams, C. R., Ziegler, D. K., \& Lin, J. T. (1983). Mercury intoxication simulating amyotrophic lateral sclerosis. Jama, 250(5), 642-643.

9. Afonso, J. F., \& de Alvarez, R. R. (1960). Effects of mercury on human gestation. American journal of obstetrics and gynecology, 80(1), 145-154. 